\title{
A Reforma da Educação - algumas reflexões
}

Maria de Lurdes Ventura Cardoso dos Santos ${ }^{1}$

The freedom to create any type of institution is an indispensable requirement for real freedom of education G. Jofre e A. Sancho

\section{Introdução}

Algumas respostas vão emergindo no âmbito do ensino, não só no Ensino Superior, para as múltiplas questões que se levantam e que vão, desde o papel que o Estado deve desempenhar na Educação, (nomeadamente na resposta à necessidade de garantir, a todos, independentemente da sua capacidade económica, a possibilidade de livremente poderem escolher o ensino que desejam realizar), até à privatização total do ensino e ao problema da escolha parental.

Propostas e soluções têm sido ensaiadas e enunciadas, em Portugal, como em diversos países, e, de uma forma ou de outra, vão tentando responder a algumas vertentes deste vasto problema.

A actualidade desta temática, onde não há soluções únicas nem infalíveis, leva-nos à apresentação deste trabalho2 onde se pretende traduzir a nossa reflexão sobre esta matéria

O entusiasmo natural de quem se vai preocupando com estas matérias, foi-nos conduzindo por verdadeiros labirintos onde cada caminho nos ia sistematicamente levar a mais uma interrogação. Assim foram surgindo questões como Ensino Público ou Ensino Privado?, Escolas Estatais ou Independentes?, Propinas, sim ou não?, The school choice choices ou não?, Escolha parental, sim ou não? Vouchers ou Tax Credits ? e tantas outras.

Algum pensamento, elaborado ao longo da caminhada por estes domínios, será apresentado neste relatório que é composto de quatro partes. Assim, depois desta pequena introdução, faremos o enquadramento teórico do tema. A seguir, apresentaremos algumas ideias sobre reformas da educação numa análise, mais ou menos pormenorizada, do texto de Lawrence Reed. 3 (2001) com especial ênfase nas novas soluções aí preconizadas. Depois, e como consequência da análise realizada, esboçaremos alguns comentários e conclusões, e para terminar, listaremos a bibliografia em que nos baseámos, de entre 0 conjunto de publicações que consultámos.

As dificuldades são óbvias, e a estrada adivinha-se longa, mas, se uma grande caminhada começa sempre por um pequeno passo, que este pequeno trabalho, possa ser o início dum estudo mais profundo, alicerçado na vontade de aprender mais, para escutar melhor, ler melhor, pensar melhor e se possível, poder ter melhor desempenho e ser mais útil aos outros.

\section{Enquadramento Teórico}

O tema que vamos abordar neste trabalho "A Reforma da Educação, algumas reflexões" apresenta alguma inovação face às metodologias reformadoras habitualmente

\footnotetext{
${ }^{1}$ Estudante do mestrado em Gestão Pública na Universidade de Aveiro, orientador de tese o Professor Doutor José Manuel Moreira. Licenciada em Matemática Aplicada na Universidade de Coimbra e Assessora do Reitor da Universidade de Aveiro.

2 Este texto traduz uma revisão do trabalho final da disciplina "Leituras Orientadas", ministrada pelo Professor José Manuel Moreira no Mestrado em Gestão Pública da Universidade de Aveiro, Portugal

30 texto base de partida foi A New Direction for Education Reform de Lawrence W. Reed, publicado em IMPRIMIS, uma publicação mensal do Hillsdale College, nos Estados Unidos, como resultado duma intervenção num Seminário realizado naquela Escola, em Maio de 2001. Lawrence W. Reed é actualmente Presidente do Centro Mackinac para as Políticas Públicas em Midland no Michigan, autor de cinco livros e centenas de artigos.
} 
usadas, numa via diferente em que soluções como o cheque ensino4 e o crédito nos impostos5, aliados a um ambiente de escolha total, criam novos cenários para uma qualidade educacional que se pretende maior.

O cheque ensino e o sistema de crédito nos impostos, aparecem como formas de subsidiar ou compensar os estudantes ou os seus pais, pelos gastos com a educação, num cenário em que o ensino não é gratuito, mas sim sujeito a mensalidades ou a propinas.

Estas soluções inserem-se portanto numa ampla problemática que passa desde logo pela questão do ensino gratuito, ou não, e a que níveis ou seja com escolas publicas e/ou privadas ou não, que por sua vez se enquadra num problemática de domínio mais vasto que abrange a definição do papel do Estado e por outro lado o papel dos pais.

Trata-se da discussão de políticas educativas e como tal de questões que não são pacíficas, nem têm certamente uma solução única, como se de um problema de matemática se tratasse, por isso vão surgindo propostas e implementadas soluções diferentes que, com vantagens nuns aspectos e desvantagens noutros, vão sendo experimentadas e avaliadas tendo em vista a melhor e maior satisfação de todos.

\section{O Papel do Estado}

O primeiro problema que se põe, desde logo, é qual deverá ser o papel do Estado em termos de educação. Será que Ihe caberá, de facto, o dever de garantir escolas e educação para todos? Públicas ou Privadas? A que níveis? Gratuitamente, ou pelo contrário, mediante o pagamento de propinas?

São inúmeros os argumentos a favor e contra a intervenção do Estado, no entanto nesta matéria parece poder afirmar-se com Gerardo Jofre e António Sancho (2001, p.125)

...the State should only intervene to the extent that its action will be beneficial. If it exceeds this limit, far from providing additional benefits, its participation will serve as distortion.

Assim, poder-se-á advogar para o Estado apenas o cumprimento das suas funções primárias, ou negativas, isto é, as que permitem garantir a ordem social, a justiça e a defesa, deixando aos cidadãos e à sociedade civil um papel interventor e empreendedor, que através dos mecanismos da economia de mercado, garantam a satisfação das necessidades dos cidadãos. A oferta de escolas privadas ou independentes que ofereçam a educação aos diversos níveis, a preços determinados pelos custos do ensino por estudante, num quadro de equilíbrio entre a oferta e a procura, permitirá aos cidadãos a possibilidade de optarem pelo ensino que desejam, incentivando a competição entre escolas que poderá ter resultados na melhoria significativa da qualidade do ensino.

Pondo em causa os princípios em que se baseia a educação, no Reino Unido, nomeadamente as Universidades, Norman Barry (2001, p. 211) vai mesmo mais longe ao afirmar

Privatisation is the only solution, so that a market determines supply, indicates the value of labour employed and maximises individual choice in their delivery

Do lado oposto, estarão certamente aqueles que defendem o normalmente designado por Estado Providência, ou mesmo Estado Papá, que deverá chamar a si as funções subsidiárias ou sociais como a saúde, a segurança social e naturalmente a educação. Neste caso, deverá responsabilizar-se pela oferta mais ou menos gratuita de uma rede de escolas e de professores, oferecendo o acesso a todos os cidadãos, podendo o ensino ser mesmo obrigatório até determinado nível.

Neste contexto, é o Estado a definir as regras e a intervir e pouco resta aos cidadãos senão aceitar o que lhes é oferecido, num mero papel de receptor ou observador, sem

\footnotetext{
4 Por não existir uma tradução directa da palavra "voucher" usaremos a designação de "cheque ensino" com esse significado

5 Por razão análoga traduziremos "tax-credit" por crédito nos impostos
} 
qualquer sentido crítico, ou interesse em formar opinião sobre o que mais lhe poderia interessar.

Entre estas duas posições opostas, poderemos naturalmente dispor de cenários diversos, com modelos mistos de funcionamento, em que o Estado, cumprindo o seu papel social, garanta, em maior ou menor grau, as condições de satisfação das necessidades educativas dos cidadãos num ambiente de liberdade e de equidade, onde as escolas públicas, privadas e independentes possam coexistir, com a qualidade que é devida.

\section{A Sociedade Moderna e o Estado Regulador}

Numa sociedade moderna e evoluída, procuramos um modelo em que o Estado se apresente como regulador, com um papel mais de árbitro do que de jogador, que defina regras de jogo claras e assegure o "jogo limpo", ou seja, que favoreça um quadro de políticas públicas propiciador do desabrochar das capacidades dos indivíduos, do empreendedorismo, do desenvolvimento económico e social, e em que a criatividade humana seja posta ao serviço do bem comum.

$E$ é neste modelo que certamente se aceitará a existência de escolas estatais que além do mais, possam assegurar a oferta de ensino em regiões onde o mercado não é competitivo nem apetecível, a par de escolas privadas que se sujeitarão a regras definidas pelo Estado que deverá zelar pelo seu cumprimento, garantindo a liberdade de escolha e a qualidade do ensino ministrado. Ou, como afirma José M. Moreira (1999, p.40)

$O$ ideal seria que o Estado garantisse um quadro em que houvesse uma concorrência limpa e saudável entre escolas estatais e privadas.

Se possível, uma sociedade em que entre o Individuo e o Estado, (no sentido de colectivo), exista uma classe intermédia, a Sociedade Civil (com a Igreja), visando finalidades públicas por meios voluntários, em que a defesa de princípios como a solidariedade propiciaria o aparecimento de escolas gratuitas, independentes, que não procurassem o lucro, antes vivessem com base em princípios de cidadania e de ética, que permitissem que aqueles que não dispõem de recursos económicos, pudessem usufruir de ensino de qualidade, mesmo sem sobrecarregar o Estado, e indirectamente, os cidadãos que pagam os impostos.

A realidade actualmente existente em muitos países, em que as escolas públicas e privadas coexistem, o problema da capacidade e possibilidade de escolha não pode deixar de se colocar.

\section{A Escolha Parental e a Escolha Total}

O problema da escolha parental é pois outra vertente deste tema onde as opiniões divergem. Há os que consideram que não é aos pais que compete escolher, porque colocar sobre eles a responsabilidade dessa decisão, principalmente sobre os mais desfavorecidos, seria um tremendo erro, uma vez que o seu desconhecimento da Escola, equivale a entregar na mão de ignorantes o futuro dos jovens, acabando por se transformar numa injustiça já que os mais ricos e esclarecidos escolherão as melhores escolas, acabando os mais pobres por ter que se restringir às de menor qualidade e portanto, desde logo, com um futuro menos promissor.

A este propósito podemos citar Norman Barry (2001, p. 225)

Some of the conventional disadvantages of private education, such as consumer ignorance and asymmetric information between ill-informed purchasers and adroit suppliers of the service in search of a quick profit, are easily overcome.

Neste contexto, advogar-se-ia também que o melhor é ser o Estado a preservar a igualdade de tratamento, definindo as regras, que habitualmente fazem associar a residência da criança à escola que deve frequentar, sem qualquer possibilidade de troca a não ser que mude de residência. Opondo-se a esta situação John Merrifield (2000, p.192) afirma 
Presently, with few exceptions, parents have school choices only if they can pay private-school tuition in addition to school taxes or if they can move to the attendance

e logo a seguir, acrescenta area of another public school.

The limited range of parental choice available now may do society more harm than good.

Por outro lado, os que defendem a escolha parental, afirmam que retirar aos pais a liberdade de escolher o ensino a ministrar aos filhos é impedi-los de os educar e procurar estruturar o seu futuro de acordo com os seus próprios desígnios, retirando-lhes um dos seus principais papéis como pais. Isto é, retirar-lhes os mais elementares direitos ou mesmo deveres relativamente aos seus filhos, 0 que se manifesta completamente inaceitável.

Os mais radicais defensores da "Escolha Educacional Total" ou simplesmente da "Escolha Total" defendem a total privatização do ensino ou seja, o total afastamento do estado de qualquer papel nesta área. Por esta via, preconizam uma maior competição entre escolas, um maior acesso ao ensino e mais estabilidade educativa.

Por outro lado, isto permitiria certamente uma maior qualidade do ensino, já que o interesse em captar alunos obrigaria a escola a esforçar-se para atingir melhor desempenho, dado que se os pais não estivessem satisfeitos com a escola dos seus filhos poderiam mudá-los para outra melhor.

De facto, como afirma Norman Barry (2001, p.225)

Consumer choice determines what is offered and high standards are maintained without supervision by the State

O problema que se levanta de imediato é a injustiça que traduz este sistema para aqueles que não tenham recursos económicos suficientes para pagar uma escola privada, certamente mais cara. Por isso, como diz José Manuel Moreira (1999, p.40)

Daí a necessidade de garantir que as famílias tenham os recursos necessários para que elas próprias adquiram a educação num mercado competitivo.

No entanto, como afirma Jonh Merrifield (2000, p. 202)

Outright privatization is not stable unless philanthropy generously supports children from low-income families. Probable continued ineffectiveness of public schools could make private-school choice and public-school choice unstable reforms.

Mas para poder escolher num mercado competitivo é imprescindível dispor de recursos económicos, próprios ou não.

\section{Quem Paga a Educação}

Uma outra importante faceta deste problema é, pois, a definição de quem deve pagar a educação.

Desde os que apelam ao ensino estatal gratuito aos diversos níveis, até aos defensores da privatização total, em que quem usufrui da educação paga-a, aparecem diferentes formas de encarar o problema e de o tentar resolver.

Para David Halpern (1994, p.143)

Quem beneficia, paga!

No entanto, isso não significa que não devam pagar indiferenciadamente, não só em função do tipo de curso, como também das capacidades económicas de que dispõem. De facto, há quem defenda que se deve ter em conta não só o próprio custo do curso, como os ganhos futuros esperados para quem o frequenta, ou mesmo o seu valor para a sociedade, ou seja, as suas externalidades.

Ou, como diz José Manuel Moreira (1999, pp. 40,41)

Já vai sendo tempo de perceber que a educação é um bem privado ...

Não será altura de pôr fim ao mito da educação gratuita (?) ......só assim se poderá garantir a autonomia do consumidor e da escola e se incentivará a liberdade e a responsabilidade de pais, professores e directores. 
Por outro lado, ao ter em conta as possibilidades económicas de cada estudante e em que medida elas condicionam ou impedem uma escolha livre, surgiram várias hipóteses de solução que têm vindo a ser implementadas em diversos países.

A experiência do Chile, com a reforma da educação de 1980, com resultados bastante interessantes, mostra-nos várias formas de ultrapassar o problema dos que não dispõem de recursos para pagar a educação. Ao nível do ensino superior, por exemplo, o recurso a empréstimos aos estudantes para o pagamento de parte ou da totalidade das mensalidades dos seus cursos, que posteriormente será pago pelo jovem licenciado, durante dez anos, a iniciar dois anos após ter terminado a sua graduação, é uma solução que tem vindo a demonstrar eficiência.

No entanto, não está isenta de críticas como, por exemplo, a de que é injusto que o reembolso do empréstimo não tenha em conta quanto ganha quem o paga. Para David Halpern (2001, p. 151)

The potential injustices of loans direct us toward a simple alternative - a tax paid on earnings.

Para ultrapassar este óbice há mesmo quem defenda algumas correcções, como por exemplo David Halpern (2001, p. 151)

A much fairer variant on the loan or general income tax model would be for graduates to pay a small surcharge on their future incomes...

Ou outras alternativas mais radicais como o designado "capital grants", ou seja um capital que é concedido ao jovem pelo Estado quando ele faz dezoito anos, e que poderá ser usado para prosseguir os estudos ou para, por exemplo, iniciar um negócio.

Embora no ponto 3. se apresentem com mais pormenor a solução do cheque ensino e do crédito nos impostos não podemos deixar de as referir neste ponto, até porque elas têm vindo a ser implementadas em vários estados e países e o seu resultado começa a ser credível e defensável por muitos.

É neste sentido que Gary Becker (1994, p. 4) afirma

Disadvantaged families cannot afford private-school tuition .... One way to remedy these defects is to give vouchers to students that they can use to help pay their tuition at any school, private or public...

\section{A Qualidade e as Reformas do Ensino}

A qualidade da educação é um tema que faz parte da ordem do dia em seminários e discussões por todo o mundo, desde os Estados Unidos a Portugal passando certamente por África ou pela Europa. Com diversas realidades e diferentes culturas, as sociedades e as escolas não conseguiram ainda atingir níveis educacionais satisfatórios e cada vez mais as dificuldades parecem persistir.

Várias são, por isso, as reformas desenvolvidas no âmbito da educação e várias as soluções em estudo e em implementação nos diferentes graus de ensino.

Lawernce W. Reed (2001, p.1), no artigo que serviu de base à nossa análise, ao falar das reformas realizadas para melhorar a qualidade da educação americana, classificaas em três categorias:

Those dealing with rules those involving resources, and those concerned with incentives.

Sendo que, na sua opinião, apenas a terceira poderá vir a dar resultados positivos.

$\mathrm{Na}$ América, como em todo o mundo, a chamada reforma baseada em regras assenta em medidas como o aumento dos períodos escolares, quer no número de horas lectivas diárias quer na duração do ano escolar, a imposição de exames nacionais, a maior exigência na certificação dos professores e na acreditação dos cursos, etc.. Este tipo de medidas, também em Portugal já sobejamente experimentadas, apenas têm conseguido alguns ganhos marginais, estando portanto longe do sucesso desejado.

Por outro lado, as reformas baseadas em recursos, são aquelas que apostam em novos livros escolares, na diminuição do número de alunos por turma, em novos equipamentos e laboratórios, em multimédia e ligação à Internet e melhores infra-estruturas 
desportivas, culturais e sociais, etc.. Conseguem gastos financeiros elevados, mas ficam muito aquém dos correspondentes benefícios educativos e de sucesso escolar. Vários estudos realizados nos Estados Unidos6 têm fornecido resultados claros sobre a inexistência duma relação clara entre gastos por estudante com medidas deste tipo e as melhorias dos resultados.

Lawrence Reed (2001, p. 1) é muito claro acerca disto, quando afirma

More Money does not equal better education. There are schools, states, and countries that spend a great deal of money per pupil with poor results, while others spend much less and do much better

É pois, com base nos fracos resultados deste tipo de reformas que L. Reed acaba por defender outra via para a educação, a que ele chama reforma baseada em incentivos, e onde retoma a ideia de Milton Friedman7sobre escolha educacional total ("Full Educational Choice"), centrada no conceito de cheque ensino.

\section{O Cheque Ensino e o Crédito nos Impostos}

O cheque ensino como pagamento directo do Estado aos indivíduos, na forma de cheque ou de cupão resgatável, tem vindo a ser posto em prática em vários estados americanos, bem como em alguns países europeus com resultados que podem ser considerados positivos, não só por permitirem a escolha parental, como pelos resultados alcançados pelos estudantes. Apesar de não existirem experiências e dados suficientes para uma avaliação global conclusiva, o saldo das experiências em curso, continua a criar expectativas positivas.

Lawrence Reed chama, no entanto, a atenção para este programa, uma vez que as mudanças legais e institucionais têm sido tão rápidas e profundas que é difícil prever os resultados da sua aplicação futura. Por outro lado, a oposição, política e social, tem sido tão forte que, por vezes, até as escolas que se poderiam candidatar à elegibilidade do cheque ensino, acabam por se retrair, com receio de consequências que as possam prejudicar, em termos da preferência dos pais.

Diversas são portanto as razões que levam à procura e à defesa de outras medidas. Politicamente mais viável, sem forte oposição espectável e que traduz uma nova solução é o designado sistema de crédito nos impostos e que consiste basicamente, numa compensação nos impostos dos pais que, em vez de escolas estatais, optem por colocar os filhos em escolas pagas, numa dedução igual às quantias gastas na educação dos filhos.

Esta medida que poderá cobrir apenas as propinas, ou mesmo estender-se a outros gastos escolares, trará certamente vantagens para os pais, na medida em que, mais do que uma redução, traduz uma diminuição nos impostos de valor igual ao que foi dispendido, até um limite fixado, e que poderá atingir metade do valor correspondente ao custo dum estudante na escola pública.

Por outro lado, em termos de opinião pública, as vantagens em relação ao cheque ensino também parecem óbvias. De facto, o sistema suportado no cheque ensino transfere dinheiro do Estado, directamente para os cidadãos, ou indirectamente para as escolas, retirando-o do fundo global dos impostos pagos pelos contribuintes o que levará naturalmente estes a pressionar o Estado para regular como, quando e onde, são gastos esses dinheiros, acabando por fazer aumentar a burocracia e a legislação a que os cidadãos se terão que submeter, para poder usufruir de uma educação mais barata.

Por outro lado, este excesso de regulação das escolas acabará por lhes tirar autonomia e capacidade de ser diferente, o que, mais tarde ou mais cedo, poderá ter como

6 James Colleman, o sociólogo responsável pela publicação "Equality of Educational Opportunity" em 1966, concluía precisamente pela falta de resultados satisfatórios, e as réplicas posteriores destes estudos, realizadas pelo economista Erik HanusheK e outros, mantêm idêntica conclusão.

7 Milton Friedman, foi professor imérito da Universidade de Chicago entre 1946 e 1976 tendo recebido o Prémio Nobel da Economia em 1976, a Medalha Presidencial da Liberdade em 1988 e a Medalha Nacional da Ciência no mesmo ano. 
consequência uma homogeneidade e até uma certa mediocridade que era exactamente 0 que a escolha total pretendia combater.

Pelo contrário, na opinião do autor em análise, o crédito nos impostos evitará estas situações uma vez que não representa dinheiro retirado do fundo dos contribuintes, até porque apenas beneficiarão dos créditos aqueles que pagarem impostos e tiverem encargos educativos, e portanto, envolve apenas dinheiro privado e voluntariamente pago.

Esta solução é realçada por Andrew Coulson8que acrescenta

Since all the money involved in these (tax credit) programs is privately and voluntarily spent, issues of church-state entanglement and necessary public oversight of public spending are rendered moot. Because of the greater resistance to regulation that follows from the absence of state funding under tax-credit programs, those programs do a better job (than vouchers) ....

De facto, de acordo com Coulson este programa assegurará as condições, historicamente consideradas de excelência educacional, nomeadamente a escolha parental, a responsabilidade parental pelo pagamento da educação dos filhos, a liberdade dos educadores, a competição entre escolas, os incentivos financeiros para educadores e o acesso universal à oferta do mercado da educação. Ao que L. Reed (2001, p.3) ainda acrescenta

Vouchers are food stamps for education, a mechanism for redistributing wealth. Tax credits are an accounting device that permits people to keep at least some of their own money that they would otherwise pay for the government-assigned school they are not using.

Por outro lado, se o Estado apenas creditar metade do que ele próprio gastaria nas escolas públicas acaba por haver uma poupança real em termos de sistema público.

\section{Críticas e Conclusões}

Mesmo entre os que defendem a escolha total como sendo o melhor sistema educacional, a opção entre cheque ensino e crédito nos impostos não é pacífica.

De facto há quem considere indevida a utilização do sistema de impostos como instrumento de engenharia social e por isso se oponha desde logo, ao sistema de crédito nos impostos para a educação. Até porque, na opinião destes, um mecanismo análogo tem sido usado no incentivo à utilização de novas tecnologias, energias não poluentes ou outras mudanças comportamentais mais recomendáveis, o que é bem diferente de educação que não deve, portanto, ser misturada, no mesmo saco.

No entanto, para outros, estas podem ser até uma forma mais simples para a maioria das pessoas uma vez que já estão familiarizadas com a sua utilização noutros domínios, e portanto isso será uma vantagem, embora também reconheçam que acabarão por ser mais um obstáculo à desejada simplificação do sistema de impostos.

As reacções negativas que os cheques ensino provocaram e as manifestações contra que fizeram eclodir, por vezes com demasiada força, levam também a que politicamente seja mais oportuna a defesa do crédito nos impostos que, à partida, não tem a conotação negativa do cheque ensino.

Um dos pontos mais fracos deste sistema de dedução nos impostos parece ser, contudo, o facto de que ele só pode ser usado por aqueles que pagam impostos, ou seja, cujos rendimentos atingem já um valor suficiente para serem tributados. Ora isto não resolve o problema daqueles para quem de facto, faria mais sentido esta preocupação. Realmente as pessoas de mais baixos rendimentos continuam afastadas da possibilidade de escolher livremente uma escola privada porque, não só não têm dinheiro para a pagar, como por este sistema, não teriam forma de ser ressarcidas das despesas feitas.

Alguns estados americanos resolveram esta questão, criando um sistema designado por "universal tuition tax credit" que permite a qualquer pessoa, independentemente de ser ou não o próprio pai, contribuir para a educação de uma criança e deduzir nos seus 
impostos, os gastos efectuados. Parece, de facto, uma via eficaz de solução, desde que devidamente acompanhada.

A utilização de campanhas específicas no sentido de escolas, igrejas, organizações sem fins lucrativos ou indivíduos aderirem ao programa de participação na educação de crianças, quer através de bolsas de estudo, quer mesmo de donativos às escolas para apoio de actividades extra curriculares, com vantagens claras nos impostos a pagar, resultaria certamente numa grande adesão a este sistema e de algum modo a solução para o problema.

Há por outro lado, quem defenda o cheque ensino apenas na medida em que ele pode ser um factor importante contra as escolas públicas, até pelas medidas que muitas vão tomando. Neste sentido, Larry Arnn (2001,p.4) diz

public schools today, which enjoy the liberty that comes with monopoly to spend our tax monies any way they please, choose to spend them on as many non-teachers as teachers.

E acrescenta ainda em relação a estes

In the best case, they do nothing. In the worst, they treat education like engineering: they draw up plans and devise new ways of teaching, leaving common sense behind.

Mas se por um lado, apoia o cheque ensino, como forma de contrariar a escola pública, acaba por lhe tecer críticas na medida em que considere existir o perigo de provocar uma excessiva regulação, o que dificultaria a vida aos cidadãos e às escolas. Ou, como L. Arnn (2001, p.4) afirma

I'm against vouchers because the regulatory system of government we live under today, unlike the limited government of the Constitution, increasingly treats private things as public. Consider the extent to which it controls how we dispose of our land and run our business. It's only a short step from that to controlling how we raise and educate our children

Por isso, considera o sistema de crédito nos impostos, proposto por Larry Reed, como uma melhoria relativamente ao cheque, embora considere que também não é perfeita, como ele diz

...tax credits is an improvement on vouchers. It's not perfect,... because it doesn't return public schools to local jurisdiction, return primary control of schools to parents, and relieve teachers of administrative oppression and union manipulation. But I'm more for tax credits than for vouchers, and less against them.

\section{Conclusão}

O modelo de incentivos com base num sistema de escolha total e num cenário de existência apenas de escolas privadas, para todos os níveis de educação é apresentado por L. Reed que considera o sistema de crédito nos impostos como o mais adequado para poder resolver o problema dos que não dispõem de recursos suficientes para oferecer aos seus filhos a possibilidade de frequentarem as escolas desejadas.

Como diz Larry Arnn, quer o modelo baseado no cheque ensino quer o baseado no crédito nos impostos é bom e mau, qualquer deles é bom no sentido que ajuda a resolver o problema da escolha parental num ambiente de escolas pagas, mas também não são bons porque não conseguem resolver todos os constrangimentos.

Embora estes cenários tenham subjacente a realidade americana, em que a população tem um grau de desenvolvimento médio muito superior ao nosso, em que as pessoas estão habituadas a participar e a exprimir através do voto e de consultas públicas a sua opinião face aos mais diversos temas, não podemos deixar de reconhecer o mérito dos princípios que subjazem a estas reformas.

Em Portugal, num cenário de menor desenvolvimento, em que a literacia da população em geral é considerada das mais baixas da Europa, onde 48 anos de fascismo ainda têm visíveis as marcas da ausência de participação cívica nos mais diversos domínios, este programa terá naturalmente que ser analisado e avaliado com unidades de medida adequadas. 
De facto, embora se tenha assistido nos últimos trinta anos a uma verdadeira massificação do ensino até ao nível superior, e se tenha vindo a apostar nos últimos tempos, no alargamento da oferta de educação pré-escolar, ampliando assim o número de anos de escolaridade obrigatória, se o Estado deixasse de ter um papel interveniente forte, como prestador, seria difícil conseguir-se melhorar os níveis de educação em Portugal.

Estamos certos, no entanto, que teremos que caminhar para um patamar de maior oferta de ensino privado, e até independente, e na diminuição do número de escolas públicas e gratuitas, garantindo uma oferta de ensino que permita uma escolha parental consciente e livre, num clima de equidade.

Se a nível de ensino superior já dispomos certamente de um número de escolas suficientes para as necessidades da população, o mesmo está ainda muito longe de ser conseguido aos outros níveis de ensino e mormente em zonas de menor desenvolvimento e densidade populacional. Nestas, teremos que continuar a garantir a oferta de ensino público, porque dificilmente se criarão condições que produzam o aparecimento de escolas não estatais

Entretanto, a análise e interpretação feitas pelo autor nas diferentes vertentes do problema, em países com um grau de desenvolvimento superior, como os Estados Unidos, não podem deixar de nos colocar questões interessantes e passíveis de produzir resultados positivos a nível da educação, mesmo no nosso país.

A aposta na diversidade e na competição entre escolas pode permitir atingir níveis de qualidade superior e custos menos elevados.

Por outro lado, sistemas como o do crédito nos impostos que aqui abordámos, em que os pais podem optar pelo ensino mais adequado, tendo para isso claros benefícios fiscais, de acordo com os gastos efectuados, trar-lhes-ão certamente vantagens não só por poderem escolher a educação que considerem adequada, de forma livre, como porque neste contexto, os resultados alcançados serão melhores.

Noutra perspectiva ainda, consideramos que ao existir um tecto para o montante a despender pelos pais para benefícios fiscais, indirectamente, as escolas sentir-se-ão obrigadas a procurar oferecer ensino a valores próximos desse limite o que certamente levará ao abaixamento dos preços praticados e até a um incentivo às escolas públicas para que consigam uma maior rentabilização dos recursos.

No contexto de gastos públicos, haverá ganhos reais, uma vez que se o Estado descontar, por aluno, metade do que gastaria se tivesse que lhe oferecer a educação, o resultado traduz uma autêntica poupança pública e eventual diminuição nos impostos dos contribuintes.

Certamente que o problema educacional dum país, seja ele mais ou menos desenvolvido, não se pode reduzir aos aspectos que aqui tratámos.

Muitas outras questões não foram abordadas no contexto desta análise. Aspectos que se prendem com a independência da investigação, com a autonomia do ensino, com a da posição da educação face aos poderes políticos e económicos, com a realidade política e social, com os constrangimentos financeiros e tantas outras, são variáveis dum amplo problema que precisamente por ser multifacetado e complexo se torna difícil encontrar soluções abrangentes e eficazes,

No entanto, no contexto deste pequeno trabalho e na vertente que aqui abordámos não podemos deixar de considerar que cada vez mais, é necessário que o Estado assuma um papel regulador e que na educação, como noutros campos, se torne um facilitador da iniciativa dos cidadãos e do seu empreendedorismo, criando as condições para que a própria sociedade civil se organize de modo que a verdadeira escolha parental se possa exercer.

Se os princípios de ética e cidadania activa se defenderem e se se criar o gosto pela entreajuda e pela solidariedade, através de soluções inovadoras e de reais incentivos, a 
nível fiscal ou outros, o Estado ajudará a fazer crescer o interesse e o nível educacional dos jovens,

Que este e outros estudos possam colaborar, para que as reformas educacionais futuras consigam fazer emergir uma sociedade mais justa porque mais livre, mais rica porque mais empreendedora, mais participativa porque mais responsável, mais feliz porque mais EDUCADA, é quanto podemos desejar.

\section{Bibliografia}

Arnn, Larry P., "The Stakes Are High", in Imprimis, vol.30, n.7, US, Julho 2001

Barry, Norman, "Privatising University Education", in Buckingham at 25 Freeing the Universities from State Control, The Institute of Economic Affairs, London, 2001. pp 211-227 Becker, Gary S., Human Capital, the Family and the State, The Mont Pèlerin Society General Meeting, Cannes, 1994, pp 1-10

Halpern, David, "Who Should Pay For HE?", in Buckingham at 25 Freeing the Universities from State Control, The Institute of Economic Affairs, London, 2001. pp 143-162

Jofre, Gerardo, Sancho, Antonio, "Higher education", in The Chilean Experience: Private Solutions to Public Problems, Fundación Libertad y Desarrollo, Santiago, 1993, pp121-152 Magnet, Myron, Paradigma Urbano As Cidades do Novo Milénio, Quetzal Editores, Lisboa, 2001

Merrifield, John D., "The School-Choice Choices", The Independent Review, v V, n.2, Fall 2000, pp189-207

Moreira, José Manuel, Ética Economia e Política, Lello \& Irmão, Porto, 2ª ed., 1996

Moreira, José Manuel, "A Educação do Estado e o Temor por Jerusalém", Nova Cidadania, n.2, Outubro de 1999, pp32-42

Murphy, Robert P., "The Origins of the Public School", The Freeman Ideas of Liberty, Julho 1998, pp 403-406

Reed, Lawrence W., "A New Direction for Education Reform", in Imprimis, vol.30, n.7, US, Julho 2001,pp 1-5 